\title{
Commentary: An equal opportunity to survive-Previous cardiac surgery is not a contraindication to type $A$ dissection repair

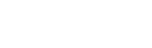

\author{
Christopher Lau, MD, and Leonard N. Girardi, MD
}

\author{
From the Department of Cardiothoracic Surgery, Weill Cornell Medical College, New York, NY. \\ Disclosures: Authors have nothing to disclose with regard to commercial support. \\ Received for publication Aug 5, 2019; accepted for publication Aug 6, 2019; available ahead of print Sept 17, 2019. \\ Address for reprints: Leonard N. Girardi, MD, 525 E 68th St, Suite M-404, New York, NY 10065 (E-mail: \\ lngirard@med.cornell.edu). \\ J Thorac Cardiovasc Surg 2020;160:18-9 \\ $0022-5223 / \$ 36.00$ \\ Copyright (c) 2019 by The American Association for Thoracic Surgery \\ https://doi.org/10.1016/j.jtcvs.2019.08.055
}

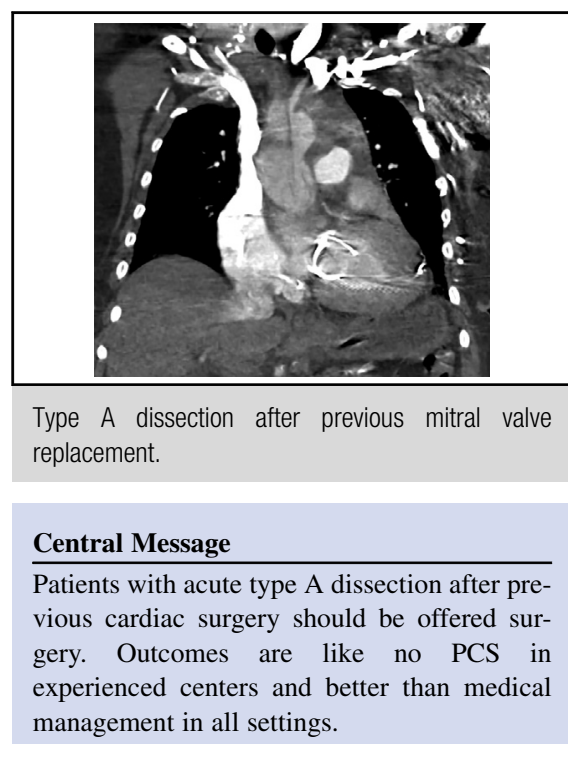

See Article page 8.
Acute type A aortic dissection (ATAAD) repair remains a challenging operation, no matter in what circumstances the patients present. Previous cardiac surgery (PCS) leads to mediastinal adhesions, which add further technical difficulties to an already complex procedure. Time is of the essence with type A dissections to prevent fatal rupture, cardiac tamponade, or malperfusion syndrome (MPS). PCS and the associated need for sternal reentry and dissection of mediastinal structures serve only to increase the time to actual aortic repair. Single-center studies have reported mortalities as high as $16.8 \%$ to $31 \%$ for ATAAD repair with PCS. ${ }^{1-3}$ This is not very different from the overall mortality with ATAAD repair in the International Registry of Acute Aortic Dissections database, however, which ranges from $18 \%$ in the recent era to $25 \%$ in previous years. ${ }^{4}$ Given that the mortality with medical management of ATAAD remains in excess of $50 \%$, it makes sense that patients with PCS should be offered a chance with surgical repair.

In this issue of The Journal of Thoracic and Cardiovascular Surgery, Norton and colleagues ${ }^{5}$ examine their outcomes with ATAAD repair in the presence of PCS, and they should be recognized for their great outcomes in this particularly tough patient population. Importantly, although the PCS group had more preoperative risk factors, there were no significant differences in postoperative outcomes in the PCS and no PCS groups, and operative mortalities were statistically similar at $12 \%$ and $8.3 \%(P=.42)$, respectively, highlighting the importance of giving these patients a chance at surgery.

The success of the Michigan group in managing these patients stems in part from their algorithm for managing patients with malperfusion syndromes with emergency endovascular fenestration followed by delayed open type A repair. Although it can be argued that this type of strict selection introduces bias in outcomes by eliminating a

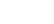

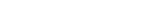


2. Klodell CT, Karimi A, Beaver TM, Hess PJ, Martin TD. Outcomes for acute type A aortic dissection: effects of previous cardiac surgery. Ann Thorac Surg. 2012;93: 1206-12; discussion 1212-4.

3. Rylski B, Desai ND, Bavaria JE, Moser W, Vallabhajosyula P, Pochettino A, et al. Type A aortic dissection after previous cardiac surgery: results of an integrated surgical approach. Ann Thorac Surg. 2014;97:1582-8; discussion 1588-9.

4. Evangelista A, Isselbacher EM, Bossone E, Gleason TG, Eusanio MD, Sechtem U, et al. Insights from the international registry of acute aortic dissection: a 20-year experience of collaborative clinical research. Circulation. 2018;137:1846-60.
5. Norton EL, Rosati CM, Kim KM, Wu X, Patel HJ, Deeb GM, et al. Is previous cardiac surgery a risk factor for open repair of acute type A aortic dissection? J Thorac Cardiovasc Surg. 2020;160:8-17.e1.

6. Chikwe J, Cavallaro P, Itagaki S, Seigerman M, Diluozzo G, Adams DH. National outcomes in acute aortic dissection: influence of surgeon and institutional volume on operative mortality. Ann Thorac Surg. 2013;95:1563-9.

7. Bashir M, Harky A, Fok M, Shaw M, Hickey GL, Grant SW, et al. Acute type A aortic dissection in the United Kingdom: surgeon volume-outcome relation. $J$ Thorac Cardiovasc Surg. 2017;154:398-406.e1. 